data shows that the prevalence of diabetes mellitus in patients with acute stroke admitted to the Roval Victoria Infirmary and Freeman Hospital, Newcastle upon Tyne, was $31 \%(24 / 78)$ as defined by a raised stable $\mathrm{HbA}_{k}(<7.5 \%$, that is, above the $95 \%$ confidence limits). There were four patients within this group with previously diagnosed diabetes mellitus, resulting in an overall incidence of unrecognised diabetes mellitus of $26 \%(20 / 78)$ There is therefore a significant number of patients with acute stroke presenting with previously unrecognised diabetes mellitus $(p<0.05)$. The group of patients presenting with a raised $\mathrm{HbA}_{k}$ value also, and not surprisingly, had a significantly higher blood glucose concentration than those with a normal $\mathrm{HbA}_{\mathrm{k}}$ value.

The report fails to emphasise the role of stress hyperglycaemia in predicting outcome, an important omission because our observed mortality rates suggest a higher mortality in those patients with stress hyperglycaemia (normal $\mathrm{HbA}_{k}$ but blood glucose $<8 \mathrm{mmol} / 1(14.4 \mathrm{mg} / 100 \mathrm{ml})$ ): $42.8 \%$ compared with $30 \%$ for diabetic patients recognised and unrecognised.

We think therefore that undiagnosed diabetes mellitus is a more important factor in acute stroke than reported but that stress hyperglycaemia is more important in predicting early mortality.

C S GRAY

I M FRENCH

K G M M ALBERTI

D BATES

Department of Neurology,

Royal Victoria Infirmary,
Newcastle upon Tyne NE1 4 L

1 Riddle MC, Hart JH. Hyperglycaemia, recognised and unrecognised, as a risk factor for stroke and transient ischaemic attacks. Stroke 1982;13:356-9.

\section{Large hepatocellular cancers: hepatic resection or liver transplantation?}

SIR, - We agree with many points made by the transplant groups in Birmingham (Mr R Kirby and colleagues) and the Royal Free Hospital (Mr H S Rogers and colleagues; 19 October, p 1122). In fact only a small proportion of cases of hepatocellular cancer referred to any particular centre will be found suitable for either transplantation or resection. Preoperative definition of irresectability can be reliable, particularly in the demonstration of multicentric disease, although, as indicated in our article, determination of resectability requires not only simple laparotomy but often extensive dissection. Despite this, all our patients selected on the basis of preoperative investigations for attempted resection were in fact resected, and of the remainder two were considered for transplantation and one accepted on to a transplant programme. None of the others were suitable for consideration of transplantation, mainly because of evidence of extrahepatic spread of disease or advanced age.

Undoubtedly, for patients with multicentric hepatocellular cancer affecting much of the liver and with no evidence of extrahepatic spread, transplantation should be considered, although the recent evidence of better results for transplantation for such disease is more blurred than is suggested by $\mathrm{Mr}$ Kirby and his colleagues. The Pittsburgh group have indeed shown good results after transplantation for cirrhosis of the liver where hepatocellular cancer was diagnosed incidentally.

However, the results continue to be indifferent when the transplantation is for multicentric and other irresectable tumours (Iwatsuki et al, personal communication). The fibrolamellar variant of hepatocellular cancer is often solitary and often occurs in the young. Resection of solitary lesions and even resection of recurrent hepatic or extrahepatic disease in some patients yields excellent results with a five year survival of about $56 \%$. $^{1}$ Since this disease seems to have a better prognosis than other forms of hepatocellular cancer, one might expect the results of transplantation for irresectable fibrolamellar hepatocellular tumours to be better also when compared with transplantation for more aggressive tumours. However, this does not negate the point that resection of even very large tumours may be preferable to ransplantation.

In fact the main point of our paper was to show the feasibility of resection in patients with very large solitary lesions even when there is evidence of vascular involvement by tumour. We attempted-it seems successfully- to draw comment from transplant surgeons on a definition of resectability and the time when such decisions can be made. We have little problem in accepting statements that transplantation should be considered if a tumour proves irresectable on defined grounds from transplant groups with a proved experience of hepatic resection. ${ }^{2-4}$ However, to suggest that all patients with primary liver cancer should be admitted to units where transplant is available, as do $\mathrm{Mr}$ Rogers and colleagues, seems unreasonable.

Liver transplants have come of age and the results are now strikingly better but transplantation for cancer still remains unproved. The vast majority of liver tumours remain both irresectable and unsuitable for transplantation. The need for capable teams undertaking transplantation on a wide basis is evident and we have been pleased to cooperate with them. However, is it really suggested that the only people capable of considering the alternatives are in units carrying a transplant team? Liver resection will continue to be the main surgical treatment for solitary liver tumours, at least in the immediate future, and it seems appropriate that many cases suitable for referral to transplantation units will continue to be assessed initially by general physicians and surgeons and by those engaged in specialist hepatobiliary surgery. Many publications attest to this and several authors, as indicated in our article, have successfully explored the possibilities of resection of very large lesions with vascular involvement.

No doubt experience and further work to define the limits of resectability and the results of both resection and transplantation will resolve differences of opinion. In the mean time we will continue to work in grateful collaboration with transplant units, and we feel that we have adequately shown our capability to select potentially suitable cases for resection or for referral for transplantation, even before laparotomy.

\section{H BLUMGART}

O SOREIDE

A CZERNIAK

Department of Surgery,

Royal Postgraduate Medical School

London W12 $0 \mathrm{HS}$

1 Soreide $\mathrm{O}$, Czerniak A, Bradpiece $\mathrm{H}$, Bloom S, Blumgart LH. Characteristics of fibrolamellar hepatocellular carcinoma: an experience of 9 cases and a review of the literature. Am 7 Surg 1985 in press

2 Starzl TE, Bell RH, Beart RW, Putnam CW. Hepatic trisegmentectomy and other liver resections. Surg Gynecol Obstet segmentectomy and
1975;141:429-38.

3 Starzl TE, Koep LJ, Weill R, 3rd. Right trisegmentectomy for hepatic neoplasms. Surg Gynecol Obsee 1980;150:208-14. 4 Starzl TE, Iwatsuki S, Shaw BW, et al. Left hepatic trisegmen ectomy. Surg Gynecol Obstet 1982;155:21-7.

\section{Social workers and the Mental Health Act 1983}

SIR,-I am perplexed by the number of general practitioners who appear to be much exercised about a change they believe to have been introduced in the 1983 Mental Health Act. While I personally think that there is little to recommend the new Act, and much that is irritating and a source of increased bureaucracy, one thing that is little different from the 1959 Act is the procedure to admit compulsorily a patient to hospital.

Under the 1983 Act the procedure in section 2 is much the same as in the $1953 \mathrm{Act}$, section 25 . After the two medical practitioners have made their recommendations an application is required. This application may be by an approved social worker or by the next of kin. The only thing that made the 1959 Act section 25 procedure different was that a close relative, rather than the next of kin, could make the application.

It is true that if the application is not by the social worker then he or she has to make a report within a reasonable time. However, a contrary view at this point would not have any legal effect in nullifying the application by the next of kin. So what, I wonder, is all the fuss about, and why is the BMA now trying to seek changes?

GEORGE J LODGE

Roundway Hospital,

Devizes SN10 5DS

* The secretary writes: "While the procedure for compulsory admission is similar to that under the 1959 Act, section 13 (4) of the Mental Health Act 1983 effectively gives the approved social workers, in making an application, the power to disregard the views of the two medical practitioners. The BMA has evidence that problems are being experienced in this context. Unlike their predecessors, the mental welfare officers, many approved social workers, have little experience in mental health and are not prepared to accept the advice of doctors-sometimes with tragic results. Efforts by the Central Council for Education and Training in Social Work to provide qualified social workers approved under the Act, supported by the BMA, have been thwarted by the refusal of the National Association of Local Government Officers to support such a qualification. Difficulties have also been experienced in finding approved social workers, and there are still parts of Britain where out of hours cover is not available. In the absence of an approved social worker the "nearest relative" can make an application under the Act; but it is often impossible to find an appropriate relative, particularly in conurbations, where the population is constantly shifting. These new provisions have placed doctors under increased pressure, and this year's annual representative meeting urged that the law giving approved social workers this power of veto should be changed."-ED, BMF.

\section{Is the distribution of training practices appropriate?}

SIR,-Dr T S Murray (21 September, p 789) asks why so few trainers come forward from certain areas-mainly areas of great deprivation. We are a training practice in the eastern district of Glasgow, which has a low proportion of trainers, and I feel from our experience that the major problem of being a trainer in an area like ours is the heavy workload. We are a practice with the equivalent of five full time partners with 9500 patients and no outside commitments. We work from an excellent health centre with generous provision of diagnostic facilities and attached staff. We have A4 records and we undertake a certain amount of screeningfor hypertension and cervical cytology.

What we can offer a trainee is excellent experience, readily available support and advice, freedom to attend any meetings or outside activities that he or she wishes, and protection from the full rigours of our heavy workload. What we cannot offer are long leisurely discussions over coffee, guaranteed uninterrupted tutorials, advanced educational aids (like videotaping of consultations), and elaborate formal assessments of the progress of the trainee. I personally find it difficult to attend many meetings away from the practice owing to the high workload. 